\title{
The structure of the e-state and public administration at the digital age
}

\author{
Alexey Barkov ${ }^{1}$, Aleksey Sokolov ${ }^{2 *}$, and Alexander Kiselev ${ }^{3}$ \\ ${ }^{1}$ Military University of the Ministry of Defense of the Russian Federation, Leningradsky Prospekt str., 55, Moscow, Russia; \\ Financial University of the Russian Federation, Volochayevskaya str., 3/4, Moscow, Russia; barkov_a_v@mail.ru \\ ${ }^{2}$ Military University of the Ministry of Defense of the Russian Federation, Volochayevskaya str., $3 / 4, \bar{M}$ Moscow, Russia, \\ srrpj@mail.ru \\ ${ }^{3}$ Military University of the Ministry of Defense of the Russian Federation, Volochayevskaya str., 3/4, Moscow, Russia; e-mail: \\ pain068@yandex.ru
}

\begin{abstract}
The introduction of information technologies into public life in all spheres of the life of the state and society has set the scientific community the task of scientific understanding of the theory and practice of the introduction and application of these technologies, modernization of the legal policy of the state in the information society. The consequence of this was the formation at the turn of the XX-XXI centuries. In the political and legal though of views on the electronic state, embodying ideas about how the state should function in the era of high technologies. Management in modern conditions begins to be built through the use of electronic communication systems at all levels. In the modern legal doctrine, the structure of the electronic state has ambiguous content. And this expresses not just the vision of the structure of the idea by various scientists, moreover, the consolidation of such provisions in scientific research is a trigger for the institutionalization of the idea, its development at the theoretical level and obtaining its expression in building its own infrastructure. The idea of an electronic state as its main goal is aimed at modernizing the public administration system through information and communication technologies and the capabilities of the global Internet. It must solve the accumulated problems and meet the criteria set by modern society.
\end{abstract}

\section{Introduction}

The structure of the e-government includes such elements ase-government, e-justice and e-democracy. But such a vision of the structure is not unambiguous, it can be refined, modified. In connection with the development of the idea of an electronic state, there is a transformation not only of management approaches in the administrative sector, but also in the corporate sphere, new approaches to management appear. The electronic state is not only a new model of interaction between the state and citizens; it is also a way of rethinking Russian statehood and Russian society through the prism of a yet unexplored, but objectively necessary system of views. For development, the state needs a new vision of its existence, taking into account the preservation of the eternal values and ideals of law. It is quite possible that it is possible to achieve debureaucratization precisely due to the implementation of the idea of an electronic state, which changes not only the approach to management, but also the very culture of interaction, mental foundations.
1. Clarification of the structural elements of the egovernment system. The peculiarities of the system as a philosophical concept lie in the fact that the elements, being combined into complexes, are forced to change. Each of the presented structural elements represents a new direction in scientific research.

2. To determine the main directions of improving public administration and the era of the electronic state. Accordingly, it is necessary to identify and characterize the ongoing changes, to make a forecast of the consequences of these changes.

\section{Research Questions}

3.1 Reforming the bureaucratic apparatus.

3.2 Providing the state with conditions for citizens to choose the form of participation in democracy.

3.3 Training of qualified personnel, responsible and servicing the resources and workflow of the electronic state.

3.4 Further implementation of the "one window" principle, incl.

\section{Problem Statement}

\footnotetext{
$\overline{\text { *Corresponding author: srrpj@mail.ru }}$
} 
3.5 Increasing the computer literacy of the population and the creation of consulting, training and accompanying centres.

3.6 Inclusion of non-state structures in the infrastructure of the electronic state.

3.7 Creation of specialized state portals, acting on the principle of an aggregator of all services provided by the state.

3.8 Development and implementation of mechanisms of state legal regulation of the sphere of implementation of the idea of an electronic state. within the framework of the integration of state and municipal standards for the provision of services.

3.9 Creation of a secure electronic document management system.

3.10 Full transfer of authorities to electronic document management.

\section{Purpose of the Study}

The purpose of the study is to determine the structural elements of the electronic state, to characterize them, as well as to identify the main directions for improving public administration in the context of digitalization.

\section{Research Methods}

The main methods used in the work are methods of empirical knowledge - comparative legal, historical and legal, formal logical methods, description, systemic method, as well as analysis, synthesis, induction and deduction methods.

\section{Findings}

1. Against the background of these processes, there are qualitative and quantitative changes in the content and essence of the idea of an electronic state. Quantitative changes are reflected in the revision of the norms of positive law and program acts, in law enforcement practice, including $\mathrm{e}$, on the organization of the functioning of the electronic state. Qualitative changes are associated with changes in systems of a higher order in relation to the electronic government. At the same time, the ideological core of the electronic state remains unchanged, which must maintain its stability even with strong opposition of legal and rational, scientific and practical, legal and corruption factors.

2. Gradually, in the Russian Federation, government officials and society are developing a value attitude towards the electronic state. In addition, it is the content of the value attitude towards it that will determine and clarify the content of the electronic state. At the moment, we believe that such a relationship has not yet been fully formed, which acts as a serious constraining factor both for further scientific research of the electronic state, and for the practice of implementing this idea in Russian conditions.

3. Now the e-government is either a way to save your time for obtaining various kinds of documents (for those citizens who have the appropriate level of computer literacy), or something inaccessible, which presents a serious problem, both temporal, intellectual, and technical (for those citizens who do not have an appropriate level of computer literacy). It seems that for state bodies and local self-government bodies, this is the sphere of the use of labor resources; these are the problems of the availability of qualified personnel, the problems of ensuring the filling of sites.

\section{Conclusion}

The structure of the electronic state can include additional elements, both inherent to it and alien, as well as - elements dictated by political and other considerations. Some researchers, such as E.G. Vasiliev and D.V. Kononenko, believe that the e-state is an integral part of e-democracy [1]. Understanding the structure largely depends on what is meant by the term "e-government".

We believe that the idea of an electronic state, being a system, is at the same time a part of a system of a higher order. Such, in our opinion, the system for the idea of an electronic state is the theory of the rule of law. Consequently, the development of the idea of an electronic state will be carried out in coordination with the development of larger-scale ideas and theories.

\section{Turning to history, you can see that the key and most basic element of the idea of e-government is e-government. P.U. speaks about this in his work. Kuznetsov, noting "the phrase"e- government" was initially used in the international Purpose of the Study}

The purpose of the study is to determine the structural elements of the electronic state, to characterize them, as well as to identify the main directions for improving public administration in the context of digitalization.

\section{Research Methods}

The main methods used in the work are methods of empirical knowledge - comparative legal, historical and legal, formal logical methods, description, systemic method, as well as analysis, synthesis, induction and deduction methods.

\section{Findings}

1. Against the background of these processes, there are qualitative and quantitative changes in the content and essence of the idea of an electronic state. Quantitative changes are reflected in the revision of the norms of positive law and program acts, in law enforcement practice, including $e$, on the organization of the functioning of the electronic state. Qualitative changes are associated with changes in systems of a higher order 
in relation to the electronic government. At the same time, the ideological core of the electronic state remains unchanged, which must maintain its stability even with strong opposition of legal and rational, scientific and practical, legal and corruption factors.

2. Gradually, in the Russian Federation, government officials and society are developing a value attitude towards the electronic state. In addition, it is the content of the value attitude towards it that will determine and clarify the content of the electronic state. At the moment, we believe that such a relationship has not yet been fully formed, which acts as a serious constraining factor both for further scientific research of the electronic state, and for the practice of implementing this idea in Russian conditions.

3. Now the e-government is either a way to save your time for obtaining various kinds of documents (for those citizens who have the appropriate level of computer literacy), or something inaccessible, which presents a serious problem, both temporal, intellectual, and technical (for those citizens who do not have an appropriate level of computer literacy). It seems that for state bodies and local self-government bodies, this is the sphere of the use of labor resources; these are the problems of the availability of qualified personnel, the problems of ensuring the filling of sites.

\section{Conclusion}

The structure of the electronic state can include additional elements, both inherent to it and alien, as well as - elements dictated by political and other considerations. Some researchers, such as E.G. Vasiliev and D.V. Kononenko, believe that the e-state is an integral part of e-democracy [1]. Understanding the structure largely depends on what is meant by the term "e-government".

We believe that the idea of an electronic state, being a system, is at the same time a part of a system of a higher order. Such, in our opinion, the system for the idea of an electronic state is the theory of the rule of law. Consequently, the development of the idea of an electronic state will be carried out in coordination with the development of larger-scale ideas and theories.

Turning to history, practice of introducing information technologies into the activities of government institutions" [2]. The use of new technologies was envisaged in the context of improving the productivity of the state apparatus, then the process of providing services began to transform in accordance with existing computer technologies and the growing needs of society. Further, changes took place in the structure of the judicial authorities, for example, in Russia this period fell at the beginning of the 21 st century, when the first sessions of the courts of general jurisdiction and arbitration courts began to be held using video conferencing. This event marked the development of the second element of e-government - e-justice.

The last element of the e-government is edemocracy, which provides for the implementation of both representative and direct democracy. Yu.V.
Nikulina points out that "through e-democracy, citizens determine what services and how they will be provided by the government, mutual responsibility is established within the framework of interaction" [3].

The embodiment of democratic principles in an electronic state is possible with the achievement of a high level of legal culture of citizens and the formation of an information society. Nevertheless, the question arises as to whether the establishment of an electronic state in a country with a monarchical form of government is possible. Note that in states such as Qatar, the United Arab Emirates, Kuwait, Saudi Arabia, Oman, Jordan, Sweden, Norway, Liechtenstein, Luxembourg, Belgium, Denmark, the Netherlands, Monaco, in which the main form of government is monarchy, the state is at a high level [4].

To date, no international rating includes an indicator reflecting the level of development of e-democracy from the standpoint of the realization of human rights and freedoms.

Considering these circumstances, we note that the development of e-democracy becomes possible in a state governed by the rule of law under a republican form of government with a democratic regime. A.A. Korobov, T.S. Melnikova, and N.V. Mityaeva support this position: "Unlike e-government, which can be implemented under both democratic and authoritarian regimes, the idea of e-democracy can find application in a state with developed democratic institutions" [5].

In states governed by the rule of law, it is advisable to maintain a balance between the need to maintain sovereignty in the information environment and preserve a democratic regime. Otherwise, very serious consequences will arise for the national statehood. Therefore, the search for a new level of management of society while preserving its national, historical and other characteristics and traditions is the most important task. In this regard, let us highlight the main directions of development of the idea of an electronic state on the example of the Russian Federation.

1. Reforming the bureaucratic apparatus.

Every year the volume of work and the load on state and municipal employees in all spheres of management is growing rapidly. Many Russian scientists pay attention to this problem. There is no doubt that this problem is urgent both in Russia and throughout the world. Accordingly, scientists, managers and legislators are trying to find the optimal mechanisms for debureaucratization.

Human participation in the managerial activity in history is of fundamental importance. However, O.N. Sinitsyn and D.A. Rakitin draws attention to the fact that "in the Russian state system, citizens are accustomed to the fact that all decisions come "from above" [6].

Accordingly, with the transition to a new management model, in which there is significant democratization of the administrative system, many Russians get the opportunity to independently communicate with government bodies without intermediaries in the face of numerous officials. Egovernment, in fact, provides a simplified way of 
interacting with authorities in comparison with personal direct contact.

2. The provision by the state of conditions for citizens to choose the form of participation in democracy.

A significant innovation for the development of an electronic state, in our opinion, is the realization of the potential of electronic democracy. This is due to the peculiarities of the state structure and management, the degree of development of civil society, the level of preparedness of state bodies and the competence of employees, as well as a number of other factors.

Of particular interest is the optimization of certain functions of government bodies, carried out through information and telecommunication technologies and computer equipment with Internet access. Taking into account the significant role of informatization of society, a natural question arises: is it possible to talk about the implementation of the idea of an electronic state, in particular, the introduction of such an element as electronic democracy, with the achievement of a complete transfer to remote interaction, or is it worth considering additional components that contribute to the modernization of lawmaking, legislative, electoral and other processes.

It is important that in the future e-voting systems be not imposed by the state as the only possible form of participation in political processes. The population should have a choice giving the right to switch to electronic participation while maintaining the traditional one. Only when the population independently chooses electronic voting as the main way to participate in elections, it will be possible to refuse paper ballots.

3. Training of qualified personnel, responsible and servicing the resources and workflow of the electronic state.

The electronic state not only relies on existing legal norms, but also aims at improving the forms and mechanisms for the exercise of citizens' rights. It is for this reason that at present, special attention is being paid to improving the qualifications of personnel who exercise their powers in government bodies and ensure the functioning of the electronic state.

Currently, according to V.Yu. Turan in, "a university graduate must have civil, professional, business, spiritual, moral, organizational, strong-willed, and intellectual qualities" [7]. Graduating from an educational institution, in fact, a specialist must be trained who meets a set of skills, knowledge and qualities that will allow him to immediately delve into the process of functioning of the electronic state.

We believe that it is necessary to create educational programs in higher educational institutions aimed at training people who will fill positions in the relevant authorities. They must have a sufficient level of knowledge to work with electronic systems, ensure their functioning, know the legislation in the field of civil, constitutional, information and other branches of law, and have the skills to work with citizens' appeals.

Thus, an e-government specialist must have knowledge and skills in the field of modern technologies and jurisprudence. This will help ensure a better work of government bodies, increase the level of accessibility of public services for citizens in order to ensure their constitutional rights and freedoms.

4. Further implementation of the "one window" principle, including.

Within the framework of the integration of state and municipal standards for the provision of services.

The process of evolution of the e-government goes from simple informing citizens about services to complex two-way interaction, in which citizens get access to all types of services of the state administration.

D.V. Kononenko points out that in modern conditions, in order to achieve the goal of communication between the state and society, it is necessary "to develop means of providing remote access for organizations and citizens to information about the activities of public authorities; provision of public services using multifunctional centers and the Internet; creation of a secure interdepartmental electronic document management system; introduction of unified departmental information systems for planning and management reporting; the formation of a regulatory legal framework" $[8]$.

Now, in Russia, state bodies of each branch of government have their own websites created on platforms, the interaction between which is either not developed or not provided at all. However, getting services on the principle of "one window" from a single website of the electronic government in Russia remains difficult.

As noted by A.F. Sokolov, "state authorities must be integrated in such a way that their information systems can exchange with each other, and all information is available from one point. This principle has proven its effectiveness in Canada, Singapore and Australia, and it is he who underlies the concept of an "electronic representative" "e-Enjoy" in the UK" [ 9]. M.S. Yakubov and U.R. Kurbaev believe that "the structure of public services should be produced in accordance with "life events" and rganized according to the principle of"one window". The main point is to provide citizens with the opportunity to receive the entire range of public services in one place" [10].

In this regard, we propose to create a single platform for the "Electronic State of the Russian Federation", which will combine the judicial system (websites of courts of general jurisdiction, commercial courts, magistrates' courts), a system of executive authorities (the State Service portal, as well as websites of regional and municipal authorities providing services) and the system of legislative authorities (consists not only in the provision of services, making an appointment, but also in the elements of e-democracy - the possibilities for the participation of the population of the municipality, the region in the adoption of laws and regulations governing legal relations in these territories).

5. Increase of computer literacy of the population and creation of consulting, training and accompanying centers.

This should also be carried out taking into account the following means: 
- Provision of state and municipal services through terminals, cable TV, as well as through other means of communication;

- Development of centers for the provision of services in electronic form in all administrativeterritorial units, the creation of their electronic nationwide map;

- The formation of a new culture of the electronic state, including the informational, legal culture of the population and the management culture of employees of state and municipal authorities.

It is necessary to form a culture of interaction between citizens and the state in the new electronic space. Otherwise, due to a lack of understanding of the ongoing processes, legal nihilism will prevail, which, as N.I. Matuzov is characteristic of the Russian mentality [11].

6. Inclusion of non-governmental structures in the infrastructure of the electronic state.

It is important that the idea of an e-government extends not only to the sphere of public administration, but and covers public relations. Unfortunately, non-state structures that provide services to citizens are not included in the e-government system. For example, the Bar is a public institution that does not belong to state authorities. It is impossible to apply through the portals of state services in order to obtain the services of a lawyer. In addition, the notary, which originated as an institution of civil society, is currently not connected to the system of providing electronic services. We believe that the designated institutions, state authorities and local self-government bodies should form a single egovernment system in order to provide the entire range of services for the population. Thus, the content of the concept of a structural element of the electronic state electronic government can be expanded.

7. Creation of specialized state portals, acting on the principle of an aggregator of all services provided by the state.

In accordance with Art. 29 of the Constitution of the Russian Federation: everyone is guaranteed freedom of thought and speech; everyone has the right to freely seek, receive, transmit, produce and distribute information in any legal way; freedom of the media is guaranteed. In accordance with this provision, timely and full provision of up-to-date data to the population on what decisions are made in municipal and state authorities and what types of services are provided by these bodies should be supported. The determining criterion for the implementation of this right is the presence of feedback from the population. Without the active participation of citizens in the activities of state and municipal authorities, it is difficult to talk about building an "electronic state" as a whole [12].

Trust and understanding on the part of the population can be achieved if the authorities themselves seek to provide the society with objective and reliable information about their decisions and actions. Citizens should receive all the information on the portal and, if they have any questions, directly contact a specialist consultant via the electronic service. Only in this case can we talk about the implementation of this mechanism in practice.

Ensuring easy adaptation and transparency of public services will significantly facilitate the transfer of interaction between the state and society to a new level. One of the main and most optimal forms of interaction between public authorities and society in the framework of the development of the idea of an electronic state is the creation of specialized state portals, acting on the principle of an aggregate of all services provided by the state. Understanding what service a user can order, what actions need to be taken, the degree of citizens' confidence in new communication methods will increase significantly.

The introduction of new technologies requires not only consistent and balanced state policy, but also the availability of special knowledge, reconstruction of the thinking style of a modern person in a rapidly progressing information space. The problems of translating the relationship between the state and society into electronic form were written by Yu.V. Soustin, D.V. Kononenko, A.A. Shanin, A.G. Madoyan, L.L. Popova, O.A. Kirekov and others.

D.S. Mikheev emphasizes, "The service delivery system is still at the stage of formation, until a verified and successful practice has taken shape. The advantages include the formed regulatory framework aimed at wide openness and publicity of procedures for the provision of municipal services" [13]. Nevertheless, problems often arise when citizens want to get a specific result, but, being confused in the wording and the actual meaning of the operation, order a different service. Of course, we are talking about special cases and over time, there should be fewer such situations. In addition, in order to avoid these problems, serious qualifications must be presented to specialists working in the field of electronic services.

Accordingly, the following are important here:

- Focus on the real needs of citizens, determined through social surveys in electronic means of communication;

- Taking into account the specifics of the needs and capabilities of various social strata and groups of the population (first of all, socially unprotected segments of the population and people with disabilities);

- The use of advanced ways of cooperation with the business sector.

8. Development and implementation of mechanisms of state legal regulation of the sphere of implementation of the idea of an electronic state.

Legislation must develop dynamically in order to keep up with new technologies introduced into the processes of interaction between government bodies and the population. Innovation is becoming increasingly important.

To date, there is an insufficiently unified state of the Russian legal framework for the electronic state, which is because the authorities have not yet come to a single legal standard that ensures the generality of the principles of government.

9. Building a secure electronic document management system. 
V.P. Kirilenko and G.V. Alekseev conclude that "it is necessary to refine the legal and administrative mechanisms for ensuring security in the area under consideration, since traditional administrative algorithms and regulations aimed at ensuring national security do not work effectively enough in the information sphere" [14]. The flexibility and efficiency of adaptation to new threats to information security, population demands, changes in technologies and legislation should also be ensured.

The adverse consequences of hacker attacks can cause serious damage to citizens and the state, legal institutions and constitutional principles. The existence of an effective method of punishment for crimes in the field of information technology becomes a preventive security measure and a measure to protect the rights and legitimate interests of citizens, as well as restore social justice.

The very fact of criminal law protection of public relations governing the production, use, distribution and protection of computer information has a preventive, preventive value. The United States has the Computer Systems Protection Act (1979), and information on cybercrimes is contained in the United States Code. The French Penal Code provides for liability for violations of human rights associated with the use of filing cabinets and data processing on computers. The Spanish Criminal Code establishes responsibility for the receipt and use of information constituting personal or family secrets in information, electronic or television filing cabinets. This gives grounds to conclude that the protection of information relations is relevant all over the world in the era of the development of the idea of an electronic state.

In addition to hacker attacks, it is possible for the population to commit crimes by submitting deliberately false information to the authorities in electronic form. In addition, on the part of municipal and state officials, the possibility of violation of the rules of law regarding personal data and other information protected by law is not excluded. Accordingly, in the electronic state, it is necessary to develop and implement a universal law providing for liability for all types of cybercrimes: both existing and possible in the future. The possibility of adopting international laws or conventions in this area is not excluded.

10. Complete transfer of authorities to electronic document management.

An important direction of improving the electronic state is the transition to electronic document management and the rejection of paper information carriers. Nevertheless, today this system is of an auxiliary nature, since when confirming legal facts, original documents with seals and signatures of officials are still required. Of course, an electronic signature is being actively implemented now, but it is not yet possible to completely abandon material carriers.

An electronic document can be recognized as eligible if the following conditions are met: there is its material analogue - a paper equivalent; the document contains the appropriate details - personal data about the person who issued it; the requirements and rules for tangible media in accordance with the law are observed.
The process of transition to electronic document management is developing in connection with the implementation in Russia of the Information Society and Electronic Russia programs, where a key element is the communication of authorities using electronic document management. Therefore, the attention of specialists in the field of public administration, politicians, legal practitioners and theoretical scientists is focused on confirming the legitimacy of electronic copies, which are much easier to counterfeit if they have sufficient skills in working with computer programs. E.V. Lapteva, D.M. Sokolova, A.V. Ermolaeva, G.A. Dvoenosova, E.R. Sultanova and others, actively pursued the study of this topic. The development of electronic document management in Russia presupposes a complete transition to electronic interaction in government by 2019 .

All these directions of development of the electronic state were initially formed in theoretical works and industry studies, then, based on the developed theoretical base, the implementation processes begin. This can be seen from the changes in the current legislation of Russia and foreign countries

\section{References}

1. E.G. Vasileva, D.V. Kononenko, Bulletin of the Volgograd state University, 1 (30), 9-16 (2016)

2. P.U. Kuznetsov Russian law journal, 3, 37-47 (2014)

3. Yu.V. Nikulina Scientific works of the Republican Institute of higher education, 15, 97-104 (2016)

4. UNE-Government Survey 2016. URL: https://publicadministration.un.org/egovkb/enus/Reports/UN-E-Government-Survey-2016 (Date of access: 20.12.2020).

5. A.A., Korobov, T.S. Melnikova, N.V. Mityaeva Formation of a public need for the development of e-government and e-democracy systems in modern Russia. (Saratov socio-economic Institute of Plekhanov Russian University of Economics, 2016).

6. O.N. Sinitsyna, D.A Rakitina. Traditional nationalcultural and spiritual values as the Foundation of innovative development of Russia, 1(7), 67-68 (2015)

7. V.Yu Turanin. The science. Art. Kultura, 2, 247251 (2015)

8. D.V Kononenko, Bulletin of Volgograd state University 2, 34-38 (2013)

9. A.F. Sokolov. Regional Economics: theory and practice, 32, 44-50 (2010)

10. M.S. Yakubov, U.R. Kubaev, Science and the World, 3 (31), 101-103 (2016)

11. N.I. Matuzov Law culture, 1, 8-24 (2012)

12. A.S. Kiselev Proceedings from Revolution and modernity (Vladimir, Russia: Vladimir branch of Ranepa, 2017)

13. D.S. Mikheev, Mari legal Bulletin, 1 (12), 50-52 (2015)

14. V.P. Kirilenko, G.V. Alekseev, Management consulting, 9(93), 21-29 (2016) 